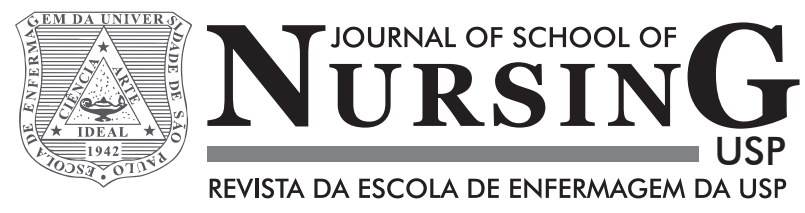

\title{
Evaluating the intervening factors in patient safety: focusing on hospital nursing staff
}

\author{
Avaliando os fatores intervenientes na segurança do paciente: \\ enfoque na equipe de enfermagem hospitalar \\ Evaluando los factores intervinientes en la seguridad del paciente: \\ enfoque en el equipo de enfermería hospitalaria
}

Roberta Meneses Oliveira ${ }^{1}$, Ilse Maria Tigre de Arruda Leitao ${ }^{1}$, Leticia Lima Aguiar ${ }^{2}$, Adriana Catarina de Souza Oliveira ${ }^{3}$, Dionisia Mateus Gazos², Lucilane Maria Sales da Silva4, Ariane Alves Barros², Renata Lopes Sampaio²

${ }^{1} \mathrm{MSc}$, State University of Ceara, Fortaleza, CE, Brazil.

${ }^{2} \mathrm{RN}$, State University of Ceara, Fortaleza, CE, Brazil.

${ }^{3} \mathrm{PhD}$, Universidad Catolica San Antonio, Spain.

${ }^{4} \mathrm{PhD}$ in Nursing, State University of Ceara, Fortaleza, CE, Brazil.

\begin{abstract}
Objective: To evaluate intervening factors in patient safety, focusing on hospital nursing staff. Method: The study is descriptive, with qualitative approach, excerpt from a larger study with analytical nature. It was undertaken in a public hospital in Fortaleza, CE, Brazil, between January and June 2013, with semi-structured interviews to 70 nurses, using Thematic Content Analysis. Results: The principal intervening factors in patient safety related to hospital nursing staff were staff dimensioning and workload, professional qualification and training, team work, being contracted to the institution, turnover and lack of job security, and bad practice/disruptive behaviors. These aspects severely interfere with the establishment of a safety culture in the hospital analyzed. Conclusion: It is necessary for managers to invest in nursing staff, so that these workers may be valued as fundamental in the promotion of patient safety, making it possible to develop competences for taking decisions with focus on the improvement of quality care.
\end{abstract}

DESCRIPTORS:

Patient Safety; Nursing Team; Nursing Staff, Hospital; Quality of Health Care. 


\section{INTRODUCTION}

The constant transformations and advances in the routine of healthcare practices, especially in the hospital setting, have impacted on the need for planning nursing staff and organizing the teams and their work processes so as to ensure safe and socially responsible care.

In parallel with the need to promote safer care, the health scenario in Brazil presents the complexity of the Unified Health System (SUS), financed by public resources and worsened by structural, political, economic, and cultural issues, which need to be overcome in order to support and improve the work environments. The media constantly reports the poor working conditions, limited resources, overcrowding, and long waiting times in the public hospitals, which expose the patient to shortcomings in the care, and which have become increasingly frequent. Such reports can feed the lay population's perception of health professionals as being inefficient ${ }^{(1)}$.

On the other hand, the interest in the human resources, today recognized as human capital, is related to the offering of better attendance to patients, due to the relationship between the perception of the health workers and their behaviors at work ${ }^{(2)}$. Today, this relationship is considered to be a fundamental aspect of putting safety into effect in the health organizations ${ }^{(3)}$.

As a result, those organizations that invest in the development of their human resources are able to reduce their staff turnover and other problems related to the management of people, through the creation of conditions that develop and make use of their human resources more efficiently ${ }^{(3)}$.

Concomitantly, the changes in the educational sector, the health sector, and the job market for nurses, over recent decades, have established the progressive need for investment in human resources through specialization courses, as a means of ensuring space in the competitive modern labor market ${ }^{(4)}$.

The nursing staff is present in all the phases of the assistential process, directly and indirectly in the care given to the patients, having the closest contact with the latter during their stays in hospital units. In this context, there is an urgent need for research describing the factors associated with the human resources in Nursing, which - positively or negatively -reflect on patient safety in the hospital context, the aim being to improve the addressing and the implementation of educational interventions so as to improve the quality of the care.

This study, therefore, aimed to evaluate the intervening factors in patient safety, with a focus on the hospital nursing staff.

This study is necessary and innovative, as it arises from initiatives promoted by the category at a national and international level, for putting into effect the culture of safety proposed by the World Health Organization (WHO) and by the Brazilian Ministry of Health's National Patient Safety Program ${ }^{(5)}$.

\section{METHOD}

The study developed had a larger scope, analytical, with a quantitative and qualitative approach, whose sample con- sisted of 70 nurses from different care units of the largest hospital in the state public network in Fortaleza, in the state of Ceará, Brazil. The researchers used the triangulation of methods for the analysis of safety culture on the perception of nurses and of records on hospital documents, such as records of Nursing occurrences book. The instruments used were $^{(1)}$ Sociodemographic and occupational questionnaire, ${ }^{(2)}$ Hospital Survey on Patient Safety Culture (HSOPSC), ${ }^{(3)}$ Semi-structured interview script, and ${ }^{(4)}$ Checklist for analysis of events related to patient safety in nursing records.

For this article in particular, there was an excerpt from this larger study, presenting the qualitative phase. The sample was the same 70 nurses from the first phase who besides accepting to participate, also considered appropriate the interview to complementarity of perception of the patient safety culture. Thus, the same 70 nurses in the first phase participated in the second phase of the study, in which a semi-structured interview script was used. As the aim was to analyze the intervening factors related to the work process of the nursing team in the hospitalized patients' safety, it was possible to categorize these factors from the perspective of nurses working in units of different complexity as well as in managerial models, degrees of leadership, and roles.

Data collection was conducted between January and June 2013 following approval from the Research Ethics Committee of the State University of Ceará (N.181.754/2012) and authorization from the hospital institution's Nursing Management.

Nurses who participated in the research met the inclusion criteria of having worked in the institution for more than 1 year and being directly involved in patient care. Those who were not present during the data collection period, for reasons of illness, medical leave, or days off, were excluded.

The semi-structured interview script addressed data on professional identification/qualification and included a guide with questions on the institution's structural and organizational aspects for promotion of patient safety.

Thematic Content Analysis was used for the analysis of the accounts, through which the corpus of the research was constituted from the 70 interviews, with phrases being defined as the registration units (RUs) and the paragraphs as the context units $(\mathrm{CUs})^{(6)}$.

The nurses were identified in the text with the letter ' $\mathrm{N}$ ' followed by an Arabic numeral, according to the order in which they were interviewed (N1, N2, etc.).

The RUs were discussed in empirical categories and presented in tables, which allows the recognition of the factors that intervene in patient safety in relation to the human resources in Nursing, as well as their frequencies in the interviewee's accounts.

It is emphasized that during the research, the guidelines on the undertaking of research involving human beings were respected. The research was undertaken following the subjects' authorization through the signing of the Terms of Free and Informed Consent. 


\section{RESULTS}

The 70 nurses surveyed in this study were predominantly female, 66 (94.3\%), had gained employment through sitting the examination of the Ceará State Health Department (SESA/CE), and had a mean age range of 33 years $( \pm 8.4)$. The other data regarding identification and professional training are shown in Table 1.

Table 1 - Characterization of the nurses interviewed in a hospital of the public network of Fortaleza-CE $(\mathrm{N}=70)$ - Fortaleza-CE, Brasil, 2013.

\begin{tabular}{|c|c|c|}
\hline Variable & $\mathbf{N}$ & $\%$ \\
\hline \multicolumn{3}{|l|}{ Age range (years) } \\
\hline $24-31$ & 44 & 62.8 \\
\hline $32-39$ & 10 & 14.3 \\
\hline $40-48$ & 16 & 22.9 \\
\hline \multicolumn{3}{|l|}{ Time since qualification (years) } \\
\hline $1-5$ & 52 & 74.3 \\
\hline $6-10$ & 3 & 4.3 \\
\hline $11-15$ & 7 & 10.0 \\
\hline 16 and more & 8 & 11.4 \\
\hline \multicolumn{3}{|l|}{ Postgraduate Qualifications } \\
\hline Specialization & 44 & 62.8 \\
\hline Master's degree & 3 & 4.3 \\
\hline None & 23 & 32.9 \\
\hline \multicolumn{3}{|l|}{ Length of work in the institution (years) } \\
\hline $1-5$ & 56 & 80.0 \\
\hline $6-10$ & 4 & 5.7 \\
\hline Over 10 & 10 & 14.3 \\
\hline \multicolumn{3}{|l|}{ Department where works } \\
\hline Emergency & 15 & 21.5 \\
\hline Inpatient unit (clinical and surgical) & 18 & 25.7 \\
\hline $\begin{array}{l}\text { Unit specializing in Cerebrovascular Accidents } \\
\text { (CVA) }\end{array}$ & 18 & 25.7 \\
\hline Intensive Care Unit (ICU) & 11 & 15.7 \\
\hline $\begin{array}{l}\text { Surgical Center and Post-Anesthesia Recovery } \\
\text { Room }\end{array}$ & 8 & 11.4 \\
\hline
\end{tabular}

A predominance of young female nurses was ascertained, who had qualified recently (up to 5 years) (74.3\%), whose time spent working in the institution was also recent (80.0\%), and who had postgraduate qualifications in various areas (62.8\%), including specialization in Medical-Surgical Nursing, Occupational Nursing and Intensive Care Nursing, among other specialities. Furthermore, they worked in various departments of the institution analyzed, divided by specialized areas.

The data depict a diverse profile of professionals, allowing the researchers to bring together the views of nurses with differing lengths of experience, leading this research to present varying perceptions on the study object.

The data obtained with the semi-structured interview allowed the researchers to grasp 70 RUs in the interviewees' discourses. These were distributed in thematic categories as may be observed in Table 2 .
Table 2 - Intervening factors in patient safety related to the hospital nursing staff. N=70 RU. - Fortaleza, CE, Brazil, 2013

\begin{tabular}{lc}
\hline Thematic categories & $\mathbf{f}(\%)$ \\
\hline Staff dimensioning and workload & $29(41.4)$ \\
Professional qualification and training & $17(24.3)$ \\
Team work & $9(12.9)$ \\
Contracted employment status, turnover and lack of & $8(11.4)$ \\
job security & $7(10.0)$ \\
Bad practice/ disruptive behaviors & $\mathbf{7 0 ( 1 0 0 . 0 )}$ \\
\hline Total & \\
\hline
\end{tabular}

\section{StAFF DIMENSIONING AND WORKLOAD}

This category represents the largest proportion of the RUs listed in the research. In this category, the nurses show a broad discourse on the relationship among the dimensioning of nursing personnel, the workload, and the performance of safe practice.

It was ascertained that the professionals who most emphasized the issue of dimensioning and workload were the nurses who worked in the emergency department and the unit specializing in cerebrovascular accidents (CVA), considered a semi-intensive care unit, recognized nationally.

The nurses from the Emergency department, however, addressed the issue from a negative point of view, considering the dimensioning of personnel to be inadequate and the service's high demands and the intense workload to be the intervening factors in patient safety, as may be observed in the accounts below:

What is most difficult here is the number of patients for the number of professionals, because there are very few professionals! (...) this is what binders our work: the overload (N8).

The principal difficulties found for safe practice are the overcrowding, the lack of materials, and the shortage of professionals (N10).

The professionals' tiredness and the long workday, I think these are the biggest difficulties for patient safety (N61).

There are a lot of patients, often when you give medication, there's no way for you to monitor bim [the patient] during the whole period; and the professionals' lack of knowledge on these [adverse] events, in which I include myself (N7).

I consider that the biggest difficulty is exactly the large number of patients and the seriousness of their conditions, it is not that it's because it's serious that it cannot be treated safely, it's not that, but the biggest difficulty is the demand (N33).

The care is undertaken superficially, they [the managers] say you have to look, change their position, but there are a lot of people, there's a lot of rush (N19). 
There's no way we can care for the patients safely because the demand is too high for so few professionals (N66).

The staff's tiredness and the long workday, I think these are the biggest difficulties (N40).

There is overcrowding here in emergency, there aren't beds available, so we have to muddle through (N17).

What makes it difficult [safe practice] is the number of patients, there are various procedures and everything is happening at the same time, so we end up leaving something or other in the care to one side (N55).

In their turn, the nurses of the unit specializing in CVAs state that the adequate numbers of Nursing professionals in that unit enable a nursing care with focus on quality, which favors the prevention and early detection of possible adverse events.

The nurse deals with few patients and gives better quality care, also she can supervise the midlevel professionals better, who also deal with few patients, and when you supervise like this, you prevent errors (N13).

In the CVA unit, there is satisfactory dimensioning of the team, as a result of which the supervision of the patient is efficient (N9).

The facilitating aspects are the good working conditions and the number of professionals in the team (N2).

We have a team with good dimensioning of the personnel, we have good engagement with the medical team and have material, in my opinion it rarely runs out (N14).

\section{Professional Qualification AND tRaining fOR SAFE PRACTICE}

In the nurses' discourses, one may also observe that the lack of professional training is a factor that hinders the implementation of safe patient care, with the need for training of the team being emphasized, the objective being a more humanized care.

I think the difficulty is the lack of training of the Nursing team, of seeing the patient in a more bumanized way (N5).

There are risks if the team is not trained (N38).

So, we 're always training somebody who doesn't know as much as is expected. Sometimes this team is immature (N29).

I think the hospital offers the material, the equipment, but what makes it difficult, what is lacking is rather the practice of the staff who work with surveillance [risk management], guiding, clarifying, running a refresher course, things like that (N3).

Some state that there are, in the service, conditions that are favorable to the performance of safe practice, through courses and training:

They offer courses, refresher courses. They [the managers] invest in the professional and in the relationship with the other colleagues who are nurses (N61).

There is training in standards/routines which aim for patient safety (N13).

I consider my unit safe, because of the training which the whole team had for working with the patient (N15).

If you are a good professional, you are going to provide appropriate care, but if you have a shortcoming, the person who'll suffer as a result is the patient, because you may commit an error (N45).

There are always courses which they provide for us. And this helps a lot, because our patient is specific, we have access to the medical team and other professionals. It's a multiprofessional team in which there is good communication (N11).

\section{TEAMWORK}

Teamwork is essential for the good functioning of any health unit, principally in institutions that aim for quality care. In this category, the nurses mention teamwork as a strengthening factor for safe practice.

First is teamwork. Here there is a physiotherapist, a doctor, an auxiliary, a nurse, and even bygienization, cleaning staff, if everybody works as a team, together, I think the errors will reduce in number or even cease (N3).

I think it depends a lot on the team wanting to, here we have a very dedicated team, so we deal well with the difficulties (N9).

Teamwork from the nursing staff [facilitates safe care] (N53).

A good interpersonal relationship with the multiprofessional team [facilitates safe care] (N5).

The team, the work engagement of the team [facilitates safe care] (N15).

\section{CONTRACTED EMPLOYMENT STATUS: TURNOVER AND LACK OF JOB STABILITY}

Another aspect addressed by the nurses that can influence the undertaking of safe care relates to the high turnover of people, students, and professionals, due to this being a teaching hospital, which ends up hindering the qualification and training of all those involved in patient care. 
As this is a state hospital, and we - the Nursing team, nurses, auxiliary nurses and nursing technicians - most of us did not gain employment here through the competitive examination we are part of a cooperative, and because of this we are subject to tremendous staff turnover, so because of this I won't remain (in the job) for very long (N17).

This is a big hospital, it's a teaching hospital, there's a bigh turnover of nursing students, of students on other courses, and of patients, and some things are really lacking here... (N20).

What has happened in this hospital is that people come here, spend a month here, they're trained... for one, two months...they get a job elsewhere with a contract, the employment card signed, and they leave. So the shifts are short-staffed. And as a result, the professional at work has to work twice as hard (N2).

What makes safe care difficult might be the lack of job security among the professionals (N17).

In relation to the cooperative, there are professionals who don't turn up to work and there isn't any way to replace them (N14).

I don't consider the hospital to be safe, due to the high rate of staff turnover (N8).

What's most lacking is nursing staff, a lot is left to be desired, because here, because of this being a state hospital, there aren't sufficient state employees, and there are more professionals from cooperatives, with no job security, so there is a strong lack of staff. There is a scarcity here of professionals and these professionals aren't contracted (N10).

\section{BAD PRACTICE/DISRUPTIVE BEHAVIORS}

Another intervening factor in the promotion of patient safety is bad practice, mentioned by only $10 \%$ of the interviewees. Bad practice is produced by professionals who act with negligence, carelessness, and incompetence and who actually resist improving their practice and promoting safe care.

The difficulties are that not everybody participates and collaborates, so I think that this is what makes it difficult most, because sometimes you can do your part, but the other person doesn't do theirs, which means that there isn't continuity (N12).

The difficulties are the lack of dedicated professionals, the negligence, carelessness and incompetence of some professionals, as well as management with little skill for managing the health service (N11).

The environment is safe, but there are professionals who work here without training, that is to say, they 're negligent, they don't even have adequate qualifications (N5).

The difficulty is there are people who you can't get through to, who don't help, who don't want to improve (N6).

Sometimes it is people who have been here for a long time, who don't want to improve, this makes our work really difficult (N11).

\section{DISCUSSION}

Addressing errors and the issue of patient safety requires a perspective directed at the human factor involved. It is known that to err is human, but, in the health care context, it is necessary for managers, leaders, and professionals to work in appropriate conditions, which minimize the occurrence of errors and of harm to the service users.

As a result, the concern with Nursing human resources has gained importance in the discussions regarding patient safety. The issues raised by the nurses directly involved in patient care indicate the main intervening factors in patient safety, which deserve to be considered by all those involved in ensuring the quality of the care given and in the hospitals' strategic planning.

Regarding the staff dimensioning and workload, the existence of a paradox in the institution was perceived; as it is a large hospital, it brings together innumerable units with differing management and work processes, which occur in dissonance with what is currently stipulated regarding the Culture of Safety in the health services.

It is known that both factors are associated with patient safety, being considered as issues widely discussed in the health area, with resources being mobilized by the $\mathrm{WHO}^{(1)}$. According to some authors, the scarce labor force in the area of Nursing in some countries, the lack of training, and the excessive workload are problems that directly compromise patient safety ${ }^{(7-10)}$.

This association between the Nursing team's workload and the occurrence of adverse events has already been proven, with falls from beds and infections related to central venous catheters. This demonstrates that an increase in the number of patients designated to each nurse or auxiliary nurse/nursing technician can increase the incidence of these events, having a negative impact on patient safety. The long workday facilitates the occurrence of adverse events and human errors caused by hurrying. These findings are similar to those presented in previous studies ${ }^{(8-10)}$.

Having enough professionals is essential for safe care. The institutions must provide favorable conditions in terms of human resources in the units and sufficient numbers of staff of adequate quality, which allow not only a lower risk of the occurrence of adverse events, but also a lower incidence of harm to the workers' health ${ }^{(11)}$.

The shortage of professionals in Brazilian public hospitals has caused large problems and difficulties for the Nursing care, as the high demand resulting from the patients only increases, while the contracting of more nurses does 
not keep up with this context of growth, as a result of which there is work overload, hindering the undertaking of quality, safe care for all the patients.

The authors state that overcrowding in public hospitals occurs because of the growing demand for hospitals, which are centers of excellence, such as the hospital of the present study. The poor ability of the primary and secondary health care to resolve health problems also contributes to this high demand. As a result, a significant proportion of Brazilian public hospitals suffers from lack of resources and feels obliged to adapt and improvise. Facts like these result in physical and psychological strain for the workers ${ }^{(12)}$.

One study analyzed the absences of the nursing staff from work in a university hospital and found that the absenteeism was considered high and was caused, above all, by periods of leave for treating health issues exceeding 15 days. Furthermore, the high monthly shortfall of nursing staff, caused by the slowness in replacing, or the failure to replace the work force, contributed to causing the work overload for the professionals. As a result, effective changes in the staff management policy and in the work processes were suggested, as was the promotion of the workers' health and safety, with a view to increasing their satisfaction with work and their commitment to the institution ${ }^{(13)}$.

Authors reiterate that the managers must make systematic use of information generated based on the application of a scientifically grounded methodology for the dimensioning of staff; however, one must note the reflection that the dimensioning of human resources as an indicator shall not be perceived as such unless it is used to relate the quantity of contracted staff to the quality of the care $^{(14)}$.

Within the category of the dimensioning of personnel, attention was called to the fact that nurses in the CVA unit perceived this aspect as positive in the service; that is to say, they considered the dimensioning of personnel to be good in the unit in which they work. This finding contradicts what was evidenced in the other units analyzed, where the nurses showed concern with the high workload due to inadequate dimensioning. Perhaps because it is a reference unit, the CVA unit has invested more heavily in its human resources, converting them into human capital, with training and follow-up in the quality of the care.

Another study corroborates the findings in the interviewees' accounts, by asserting that the appropriate dimensioning of nursing workers in the intensive care unit (ICU) favors working conditions for achieving quality, safe nursing care, both for those who care (the nursing worker) and for those who are cared for (the patient) $)^{(11)}$.

It is also important to note that not only absenteeism results in adverse outcomes for patients, health professionals, and hospitals but the presenteeism is also noteworthy, consisting in reduced on-the-job productivity as a result of health problems.

Recent research in the United States has investigated the extent to which musculoskeletal pain or depression (or both) in nurses affects their work productivity and self-reported quality of care and considered the associated costs.
Among the respondents (2,500 hospital-employed nurses), the prevalence of musculoskeletal pain was $71 \%$ and that of depression was $18 \%$. The majority of respondents (62\%) reported a presenteeism score of at least 1 on a 0 to 10 scale, indicating that health problems had affected work productivity by at least a little. Pain and depression were significantly associated with presenteeism, which was significantly associated with a higher number of patient falls and medication errors, and lower quality-of-care scores ${ }^{(15)}$.

A Brazilian study addressed presenteeism in 129 hospital nurses working in direct care delivery to critical and potentially critical patients and found $75 \%$ of nurses with a lost productivity index of up to $4.84 \%$. The physical demand domain represented the major limitation for these professionals (25\%). Presenteeism was directly correlated to health care, occurrence, and number of absences and was indirectly related to work time at the unit. The authors concluded that organizational or individual factors influence individuals' productivity, in view of the circumstances involving care delivery to critical and potentially critical patients ${ }^{(16)}$.

A cross-sectional survey of nurses and patients in 12 countries in Europe and the United States determined whether hospitals with a good organization of care (such as improved nurse staffing and work environments) could affect patient care and nurse workforce stability in European countries ${ }^{(17)}$.

High rates of nurse burnout [10\% (Netherlands) to $78 \%$ (Greece)], job dissatisfaction [11\% (Netherlands) to 56\% (Greece)], and intention to leave [14\% (US) to 49\% (Finland, Greece)] were found in that survey. Improved work environments and reduced ratios of patients to nurses were associated with increased care quality and patient satisfaction. In the European hospitals, after adjusting for hospital and nurse characteristics, nurses with better work environments were half as likely to report poor or fair care quality and give their hospitals poor or failing grades on patient safety. Each additional patient per nurse increased the odds of nurses reporting poor or fair quality care and poor or failing safety grades. Patients in hospitals with better work environments were more likely to rate their hospital highly and recommend their hospitals, whereas those in hospitals with higher ratios of patients to nurses were less likely to rate them highly or recommend them. Results were similar in the United States ${ }^{(17)}$.

This context explains the existence of a vicious circle in which the lack of investment in human resources in Nursing entails greater work overload, stress, errors, and adverse events. These, in turn, increase the patients' time spent receiving inpatient treatment and impact on innumerable other structural and care indicators for the quality of the service, requiring continuous efforts from a team, which is little-valued in the context of participation in the planning of organizational changes.

The results of another Brazilian study provide evidence against a fixed workload in the ICUs and pose new challenges for nursing managers: select or develop different tools for measuring nursing workload and find new models for nursing staff allocation to assure patient safety, improve 
quality of care, and balance cost-effectiveness and quality in the $\mathrm{ICUs}^{(18)}$.

The prevention and control of the occurrence of adverse events requires, therefore, material and human investments and involves costs and political will, if it is to implement actions of change in the dynamics and in the working conditions. Thus, all of the nurses' efforts for confronting these occurrences are insufficient if a process of partnership between the institution and these professionals is absent, in the sense of there being an ethical commitment and the creation of institutional goals with the aim of prizing the patient's safety and integrity ${ }^{(19)}$.

Regarding professional qualification and training, when the interviewees mention the need for training and knowledge relating to the nomenclatures, which permeate patient safety, such as adverse events, their concern with developing the culture of safety is evident. This finding deserves the attention and involvement of the managers, so as to promote greater integration of the continuous education service with the professionals involved directly in care.

In this context, it has been disseminated that institutions that have an adequate number of nurses with greater professional qualification have better results in health and in the promotion of safety, with reduction in the rates of nosocomial infections, falls, pressure ulcers, and medication errors, contributing to significant decreases in length of stay in the health institutions and in patient mortality ${ }^{(20)}$.

For this, the hospital institution has the responsibility to propose programs for team education regarding clear and precise concepts relating to what adverse events are, what types there are, and the importance of their recording and notification $^{(21)}$, qualifying them for new care demands or changes in the care process ${ }^{(22)}$.

Regarding teamwork, it is known that this is essential for the good functioning of any health service, and what was observed was that the nurses demonstrated good integration and expectations regarding the work. In relation to this aspect, the nurses mentioned teamwork as a strengthening factor for safe practice.

Teamwork is based on the premise that each professional respects the other's limits and time, which is essential for safe, quality Nursing. One study demonstrated that teamwork creates a high level of satisfaction and a reduction in mortality rates ${ }^{(23)}$.

Another study contends that the dimensioning of adequate personnel and absenteeism are aspects that significantly influence teamwork ${ }^{(24)}$, deserving attention from leaders in the health services.

Regarding the issue of contracted employment status, turnover and lack of job security, it is known that these factors also constitute a barrier to ensuring patient safety.

In this perspective, the health workforce has evidence of its undervaluing translated by the process of deregulation of the work, which is expressed through problems such as the disruption in the planning of the services, the lack of continuity of the assistential programs, the intensification of the workday through taking on more than one job, the low pay, the high turnover, the insufficient numbers or quality of staff, and the precarious working conditions that compromise a qualified intervention and put the service users' lives at risk ${ }^{(25)}$.

In Brazil, this current health situation leads to the undervaluing of the work of Nursing, with the contracting of professionals from agencies or on a short-term basis and without the appropriate training. This context causes these professionals to seek more than one job so as to meet their needs, causing stress, physical and emotional tiredness, overload of work, and, in many cases, burnout syndrome.

This increase in turnover and in the precariousness in the work in Nursing is a worldwide problem, in the clear meaning that the world is changing and Nursing, aging. Economic changes and the impact of the global financial crisis and the recession are factors that predispose to the crisis in the area of health and, in particular, in Nursing ${ }^{(26)}$.

The repercussions of the turnover for the hospital area are innumerable, such as discontent in the team, resulting from overload of tasks for the members who remain in the hospital; drops in production and in the quality of the services; lack of knowledge and technical skills in recently admitted professionals, causing lack of safety for the patients who they assist; and recruitment and selection costs ${ }^{(27)}$.

This study corroborates the scientific evidence regarding the importance of the high turnover among nurses, especially in terms of negative consequences. For example, a study in Canada showed that the turnover among nurses is a big problem there, with a significant turnover rate of $19.9 \%$ in the hospitals; higher levels of ambiguity and role conflict were associated with higher rates of turnover; the highest rates of turnover were associated with the deterioration of the workers' mental health, lower satisfaction in the work, and an increase in the probability of errors ${ }^{(28)}$.

A recent multicentric study undertaken over 6 consecutive months in 141 hospitals examined the impact of nursing staff turnover on the patients' results. For this, the work processes (group cohesion, relational coordination, learning, and work group coordination) and the patient's progression - in terms of falls, medication errors, and patient satisfaction indices - were measured. It was found that the units with moderate levels of turnover were prone to have lower levels of work group learning when compared with those with no turnover $(\mathrm{p}<0.01)$, while nursing units with low levels of turnover were prone to have fewer falls among patients than nursing units with no rotation $(p<0.05)$. Furthermore, the cohesion of the work group and the relational coordination had a positive impact on patient satisfaction $(\mathrm{p}<0.01)$ and increased learning, leading to fewer occurrences of serious medication errors $(\mathrm{p}<0.05)^{(29)}$.

The clinical relevance of the study implies that the management of the turnover of Nursing within appropriate levels is fundamental for allowing high quality care for the patient ${ }^{(25)}$.

As a result, there is a growing concern among managers with how these inadequate work conditions affect the adoption of inappropriate behaviors that cause harm to the patients - that is, the adoption of bad practice in the work environment as a consequence of outdated models of management, low salaries, the precariousness of the services, and the poor working conditions in place. 
Finally, regarding bad practice, it is known that inappropriate behaviors at work are being targeted by researchers worldwide. These are behaviors that cause failures in communication and harm to patients.

Many of those who adopt these behaviors are professionals who have been qualified longest, often being resistant to changes in their work environment through fear of the new, and also because of believing that they are more experienced than the other nurses due to the length of their service in the institution. Some are not open to interdisciplinary and interdepartmental communication, expressing a nonparticipative attitude, which hinders the dynamics of the service.

In analyzing the doctors' and nurses' work, the researchers observed a significant relationship between inappropriate behaviors and worrying behavioral and psychological traits. These conducts led to the impairment of work relationships, evidenced by intimidation, hostility, stress, frustration, loss of focus, poor communication, and reduction of transference of information. The researchers also identified that these attributes directly affect the results of the care given to the patient ${ }^{(30,31)}$.

In this scenario, the innumerable gaps currently involved in the process of the training of the health professional are interfering aspects. Instead of being critical, reflexive professionals able to take assertive decisions in the ambit of their practice, those finishing the courses in the health area often lack the ability to build a health system that is safer, more ethical, and better able to meet its users' needs.

In this perspective, the organizations' major differential must be concentrated in the personnel and in the teams' professional performance. The organizations' technology and structure may have but little significance if the personnel do not feel committed to quality and meeting the clients' needs, and, for this to occur, it is essential for the organization to have a communication network that is effective and resolutive regarding the routine situations that underlie the management of quality ${ }^{(32)}$.

Well-informed workers have a higher probability of being more motivated and proud of their roles, it being im- possible to obtain a good quality program without good communication $^{(32)}$.

Interdisciplinarity, in the context of health work, is a process in construction, in which various professionals are involved, in search of a common objective: comprehensive care for the service users. In this process, some elements are indispensable: authentic communication, dialog, respect, and recognition of what each one of the professionals knows and does, and the possibility of participating in decision-making $^{(33)}$.

\section{CONCLUSIONS}

The investigation allowed the understanding of the magnitude of the variables related to the human resources in nursing, and of how these relate to safety in health. It also allowed the better understanding of the aspects of the assistential contexts of the units studied: complex and determinant due to emphasizing the intervening factors of patient safety, which have a strong relationship with the management of human resources.

One of this study's important findings was the observation that the dimensioning of nursing personnel, the qualification, and the training of the team are aspects with high influence in the implementation of safe care practices, increasing the probability of the occurrence of risks to the safety of the patients and the professionals, if not planned and executed efficiently.

Contracted employment status and job security are two facets of a single dimension, which are closely linked to the regulation of the work and which are expressed in the unit studied as a management and organizational problem but, above all, also as a political problem to do with State employees, and which cause changes in human behavior in the work standards, and in the organizational values.

Knowledge of the aspects that intervene in patient safety, with a focus on the human resources, requires careful, in-depth study. Further investigations are, therefore, needed in order to establish significant associations between the management of patients and safety in health.

\section{RESUMO}

Objetivo: Avaliar fatores intervenientes na segurança do paciente, com enfoque na equipe de Enfermagem hospitalar. Método: Estudo descritivo, com abordagem qualitativa, recorte de pesquisa de maior abrangência de caráter analítico. Desenvolveu-se em um hospital público de Fortaleza, CE, Brasil, entre janeiro a junho de 2013, por meio entrevistas semiestruturadas com 70 enfermeiros assistenciais, empregando-se Análise de Conteúdo Temática. Resultados: Os principais fatores intervenientes na segurança do paciente relacionados à equipe de Enfermagem encontrados foram: dimensionamento de pessoal e carga de trabalho; formação e capacitação profissional; trabalho em equipe; vínculo empregatício, rotatividade e falta de estabilidade; má prática/comportamentos destrutivos. Tais aspectos interferem sobremaneira no estabelecimento da cultura de segurança na instituição analisada. Conclusão: São necessários investimentos, por parte dos gestores, nos recursos humanos de Enfermagem, para que estes trabalhadores sejam valorizados como fundamentais na promoção da segurança do paciente, possibilitando o desenvolvimento de competências para a tomada de decisão com foco na melhoria da qualidade assistencial.

DESCRITORES:

Segurança do Paciente; Equipe de Enfermagem; Recursos Humanos de Enfermagem no Hospital; Qualidade da Assistência à Saúde. 


\section{RESUMEN}

Objetivo: Evaluar los factores intervinientes en la seguridad del paciente, con énfasis en el equipo de Enfermería hospitalaria. Método: Estudio descriptivo, con abordaje cualitativo, recorte de investigación de mayor alcance de carácter analítico. Se desarrolló en un hospital público de Fortaleza, CE, Brasil, entre enero y junio de 2013, por medio de entrevistas semiestructuradas con 70 enfermeros asistenciales, empleándose el Análisis de Contenido Temático. Resultados: Los principales factores intervinientes en la seguridad del paciente relacionados con el equipo de Enfermería encontrados fueron: dimensionamiento de personal y carga laboral; formación y capacitación profesional; trabajo en equipo; vínculo de empleo, rotatividad y falta de estabilidad; mala práctica/comportamientos destructivos. Dichos aspectos interfieren demasiado en el planteamiento de la cultura de seguridad de la institución analizada. Conclusión: Son necesarias inversiones, por parte de los gestores, en los recursos humanos de Enfermería, para que se valoren esos trabajadores como fundamentales en la promoción de la seguridad del paciente, posibilitando el desarrollo de competencias para la toma de decisiones con énfasis en la mejoría de la calidad asistencial.

\section{DESCRIPTORES:}

Seguridad del Paciente; Grupo de Enfermería; Personal de Enfermería en Hospital; Calidad de la Atención de Salud.

\section{REFERENCES}

1. Magalhães AMM, Dall'Agnol CM, Marck PB. Nursing workload and patient safety: a mixed method study with an ecological restorative approach. Rev Lat Am Enfermagem. 2013;21(n.spe):146-54.

2. Yepes-Baldó M, Romeo M, Berger R. Human Capital Questionnaire: assessment of European nurses' perceptions as indicators of human capital quality. Nurs Health Sci. 2013;15(2):229-34.

3. Rondeau KV, Williams ES, Wagar TH. Developing human capital: what is the impact on nurse turnover? J Nurs Manag. 2009;17(6):739-48.

4. Barbosa TSC, Almeida Filho AJ, Santos TCF, Gomes MLB, Oliveira AB, Souza MCF. Políticas de saúde e educação e a oferta dos cursos de especialização em enfermagem - 2001-2007. Rev Enferm UERJ. 2011;19(2):292-8.

5. Brasil. Ministério da Saúde. Portaria n. 529/GM, de $1^{\circ}$ de abril de 2013. Institui o Programa Nacional de Segurança do Paciente [Internet]. Brasília; 2013 [citado 2014 maio 5]. Disponível em: http://bvsms.saude.gov.br/bvs/saudelegis/gm/2013/prt0529_01_04_2013.html

6. Bardin L. Análise de conteúdo. Lisboa: Edições 70; 2010.

7. O'Brien-Pallas LLIXM, Wang S, Meyer RMM, Thomson D. Evaluation of a patient care delivery model: system outcomes in acute cardiac care. Can J Nurs Res. 2010;42(4):98-120.

8. Harless DW, Mark BA. Nurse staffing and quality of care with direct measurement of inpatient staffing. Med Care. 2010;48(7):659-63.

9. Needleman J, Buerhaus P, Pankratz VS, Leibson CL, Stevens SR, Harris M. Nurse staffing and inpatient hospital mortality. N Engl J Med. 2011;364(11):1037-45.

10. Gonçalves LA, Andolhe R, Oliveira EM, Barbosa RL, FaroACM, Gallotti RMD, etal. Nursing allocation andadverse events/incidents in intensivecare units. RevEsc Enferm USP [Internet].2012 [cited2014May5];46(n.spe):71-7.Availablefrom:http://www.scielo.br/pdf/reeusp/v46nspe/en_11.pdf

11. Inoue KC, Matsuda L M. Sizing the nursing staff in an intensive care unit for adults. Acta Paul Enferm [Internet]. 2010 [cited 2014 May 5];23(3):379-84. Available from: http://www.scielo.br/pdf/ape/v23n3/en_v23n3a11.pdf

12. Garlet ER, Lima MADS, Santos JLG, Marques GQ. Organização do trabalho de uma equipe de saúde no atendimento ao usuário em situações de urgência e emergência. Texto Contexto Enferm. 2009;18(2):266-72.

13. Fakih FT, Tanaka LH, Carmagnani MIS. Nursing staff absences in the emergency room of a university hospital. Acta Paul Enferm [Internet]. 2012 [cited 2014 May 5];25(3):378-85. Available from: http://www.scielo.br/pdf/ape/v25n3/en_v25n3a10.pdf

14. Vituri DW, Lima SM, Kuwabara CCT, Gil RB, Évora YDM. Dimensionamento de enfermagem hospitalar: modelo OPAS/OMS. Texto Contexto Enferm. 2011;20(3):547-56.

15. Letvak SA, Ruhm CJ, Gupta SN. Nurses' presenteeism and its effects on self-reported quality of care and costs. Am J Nurs. 2012;112(2):30-8.

16. Umann J, Guido LA, Grazziano ES. Presenteeism in hospital nurses. Rev. Latino-Am. Enfermagem [Internet]. 2012 [cited 2014 Aug 6];20(1):159-66. Available from: http://www.scielo.br/pdf/rlae/v20n1/21.pdf

17. Aiken LH, Sermeus W, Heede KVH, Sloane DM, Busse R, McKee M, et al. Patient safety, satisfaction, and quality of hospital care: cross sectional surveys of nurses and patients in 12 countries in Europe and the United States. BMJ. 2012;344:e1717.

18. Padilha KG, Sousa RMC, Garcia PC, Bento SCT, Finardi EM, Hatarashi RH. Nursing workload and staff allocation in na ICU. Intens Crit Care Nurs. 2010;26(2):108-13.

19. Vargas MAO, Ramos FRS. Iatrogenesis in Intensive Care Units: dramatization of Contemporary Bio/Ethical Problems. Rev Lat Am Enfermagem [Internet]. 2010 [cited 2014 May 5];18(5):990-7. Available from: http://www.scielo.br/pdf/rlae/v18n5/21.pdf

20. Pedreira MLG. Práticas de enfermagem baseadas em evidências para promover a segurança do paciente. Acta Paul Enferm. 2009;22(n.esp.):880-1.

21. Kuwabara CCT, ÉvoraYDM, Oliveira MMB. Risk management in technovigilance: construction and validation of a medical-hospital productevaluation instrument. Rev Lat Am Enfermagem [Internet]. 2010 [cited 2014 May 5];18(5):943-51. Available from: http://www.scielo.br/pdf/rlae/v18n5/15.pdf

22. Vargas MAO, Luz AMH. Práticas seguras do/no cuidado de enfermagem no contexto hospitalar: é preciso pensar sobre isso e aquilo. Enferm Foco. 2010;1(1):23-27.

23. Kalisch BJ, Lee KH, Rochman M. Nursing staff teamwork and job satisfaction. J Nurs Manag [Internet]. 2010 [cited 2013 June 11];18(8):93847. Available from: http://www.ncbi.nlm.nih.gov/pmc/articles/PMC2994317/ 
24. Kalisch BJ, Lee KH. Variations of nursing teamwork by hospital, patient unit, and staff characteristics. Appl Nurs Res. 2013;26(1):2-9.

25. Souza MASL. As novas configurações do trabalho em saúde: os indicativos do processo de desregulamentação. Textos Contexto Enferm. 2010;9(2):334-44.

26. Buchan J. Nurses' turnover: reviewing the evidence, heeding the results? JAdv Nurs. 2013;69(9):1917-8.

27. Oliveira SAO, Paiva RFR. Possibilidade de diminuir o turnover da equipe de Enfermagem nos serviços hospitalares. Rev GestãoSaúde 2011;2(1):60-73.

28. O'Brien-Pallas L, Murphy GT, Shamian J, Li X, Hayes LJ. Impact and determinants of nurse turnover: a pan-Canadian study. J Nurs Manag. 2010;18(8):1073-86.

29. Bae SH, Mark B, Fried B. Impact of nursing unit turnover on patient outcomes in hospitals. J Nurs Scholarsh. 2010;42(1):40-9.

30. Rosenstein AH. Managing disruptive behaviors in the health care setting: focus on obstetrics services. Am J Obstet Gynecol. 2011;204(3):187-92.

31. Rosenstein AH, Naylor B. Incidence and impact of physician and nurse disruptive behaviors in the emergency department. J Emerg Med. 2011;43(1):139-48.

32. Figueiredo MB, Brito MJM, Alves M. Influência da comunicação no processo de acreditação hospitalar. Rev Bras Enferm. $2013 ; 66(1): 46-51$.

33. Matos E, Pires DEP, Campos GWS. Relações de trabalho em equipes interdisciplinares: contribuições para a constituição de novas formas de organização do trabalho em saúde. Rev Bras Enferm. 2009; 62(6):863-9. 